\title{
Practically Feasible Closed-Loop Digital Predistortion for VCSEL-MMF-Based Radio-over-Fiber Links
}

\author{
Muhammad Usman HADI ${ }^{1,2}$, Jacopo NANNI ${ }^{1}$, Olivier VENARD ${ }^{2}$, \\ Geneviève BAUDOIN ${ }^{2}$, Jean-Luc POLLEUX ${ }^{2}$, Giovanni TARTARINI ${ }^{1}$ \\ ${ }^{1}$ Dept. of Electronic and Information Engineering, University of Bologna, Viale Risorgmento 2, 40136 Bologna, Italy \\ ${ }^{2}$ ESYCOM-CNRS, ESIEE Paris, Université Paris-Est, 2 Boulevard Blaise Pascal, 93160 Noisy-le-Grand, France \\ \{muhammadusman.hadi2,jacopo.nanni3, giovanni.tartarini\}@unibo.it \\ \{ muhammadusman.hadi, olivier.venard, genevieve.baudoin, jean-luc.polleux $\}$ esiee.fr
}

Submitted September 9, 2019 / Accepted November 26, 2019

\begin{abstract}
The article demonstrates a novel Digital Predistortion (DPD) architecture for Mobile Front Haul links for the advanced Long-Term Evolution (LTE) and upcoming $5 G$ networks. Precisely, the use of a feedback approximation method has been proposed and experimentally demonstrated herein that simplifies the complexities in realizing the practical DPD technique for Multi-Mode VCSELs and Multi-Mode Fibers based Radio over Fiber systems. As a figure of merit, linearization efficiency is provided in terms of Adjacent Channel Power Ratio, Normalized Mean Square Error and Error Vector Magnitude referring to a complete LTE frame occupying $10 \mathrm{MHz}$ with 256-QAM modulation format.
\end{abstract}

\section{Keywords}

Radio over fiber (RoF), Indirect Learning Architecture (ILA), Digital Predistortion (DPD), Adjacent Channel Power Ratio (ACPR), Vertical Cavity Surface Emitting Lasers (VCSEL), Long Term Evolution (LTE)

\section{Introduction}

Radio-over-fiber (RoF) is an empowering methodology for the upcoming fifth generation fronthaul networks due to the advantages it provides such as broad band connectivity and low latency [1], [2]. It brings additional advantages such as resource sharing, small footprints and decreasing the overall cost. For this reason, in principle, Analog Radio over Fiber (A-RoF) can be regarded as an attractive economical technology compared to other RoF technologies, such as Digital RoF (D-RoF) [3] and Sigma Delta RoF (S-DRoF) [4].

RoF is a suitable technology to cope with the on growing demand of high bandwidth multivariate wireless services both for outdoor and indoor scenarios [5-7], and is looked upon as an enabling technology for next generation networks [8], [9].

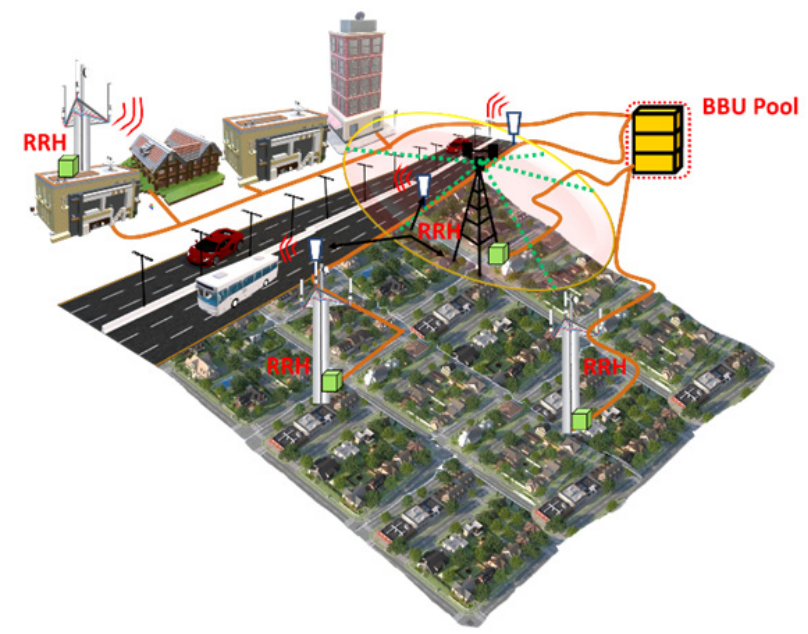

Fig. 1. RoF application for the wireless coverage connectivity.

Moreover, thanks to the low attenuation of the optical fiber, the radio signals can be transmitted with a reduced need of repeaters or amplifiers. Not only for long distance applications, but also for short distances, RoF fronthaul systems link several Remote Radio Heads (RRH) to the baseband unit (BBU) [10]. In particular, RoF technology can provide an essential platform for building centralized/cloud radio access network (C-RAN) which should be able to control the centralized base band units (BBU) coming from many base stations and remote radio heads (RRHs). The interconnectivity of these BBUs with RRHs is economically viable with the distribution network known as the 'fronthaul' [11], [12]. The RoF technology is then a suitable candidate for the fronthauling due to its inherent capillary properties. The conceptualization is demonstrated in Fig. 1.

In short range networks the nonlinearities that arise due to amalgamation of fiber chromatic dispersion and laser frequency chirp are inconsequential [13], while the impairments due to laser and, with typically lower impact, to photodiode, are primary concerns. Hence, this results in high distortion in inter and intra-bands, eventually results in increase of the interference with near channels and a low quality of transmission. 
The RoF short medium network based on Standard Single mode Fiber (SSMF) or Multimode Fiber (MMF) has been reported in [14]. In both cases, a possible solution which keeps cost and power consumption at low levels can be obtained utilizing Vertical Cavity Surface Emitting Lasers (VCSELs) emitting in the first optical window (wavelength $\lambda=850 \mathrm{~nm}$ ) as optical source.

Since the use of 850 -nm VCSELs in combination with MMFs is a relatively centralized choice finding application e.g. within data centers [15], care must be taken in front of the possible impairments due to the multimodal behavior of SSMFs operating at $850 \mathrm{~nm}$. This multimodal behavior would indeed be absent if higher cost VCSELs operating at $1.3 \mu \mathrm{m}$ and $1.55 \mu \mathrm{m}$ were utilized, in which cases the major SSMF-related impairments could just be ascribed to optical nonlinear effects and/or to chromatic dispersion. However, appropriate countermeasures have been proposed, which can prevent this last impairment cause to be critical [16], [17].

The problem is particularly present in RoF systems that utilize Vertical Cavity Surface Emitting Lasers (VCSELs). Indeed, these systems, which beside mobile fronthauling [10-12], find applications in ever-changing scenarios like indoor distribution of wireless signals [18], machine learning methods [19] and radio astronomy [20], are attractive because these optical sources feature low cost and low power consumption.

However, in Long Term Evolution (LTE), and 5G NR signals suggest the use of Orthogonal Frequency Division Multiplexed (OFDM) signals which present high Peak-toAverage Power Ratio (PAPR), e.g., VCSEL-based optical systems generate undesired spurious terms. As mentioned, in short range networks the primary causes are typically fiber independent, namely nonlinear characteristic curves and little VCSELs dynamic range and, with typically lower impact, possible nonlinearities of the photodiode response curve.

Digital Predistortion (DPD) has proven to be a worthwhile method that leads to reduction of the nonlinearities in RoF systems [21-24], and in this context Indirect Learning Architecture (ILA) is utilized for the DPD identification [21-27]. The primary intension behind this method utilizes a digital predistorter (PD) which has inverse and nonlinear profile to that of the Radio over Fiber system. Consequently, when cascaded with the RoF system, it will lead to linearization of the overall cascaded system. DPD linearization technique using memory polynomials based on Volterra series has been applied to Nonlinear RoF link [21-26]. Similarly, the Digital Predistortion technique based on canonical piecewise-linear (CPWL) function was proposed for intensity modulated/direct detection RoF system [26], [27]. All the aforementioned techniques apply the distortion compensation considering the RoF systems as "black box".

The practical realizability of an effective predistortion requires that at the so-called pre-distortion training block, which is typically located at the Central Office (CO), a feedback signal which replicates the output of the transmission system is made available. In [24], a RoF uplink was suggested for transmitting the feedback RF signals. However, this solution tends to increase the overall cost, but also brings the necessity to carefully handle its own nonlinearities. These could be in turn compensated, as envisaged in [25], through an appropriate CO-located digital post distorter block. It appears that in this system, the price to pay is to set more signal processing devices at the Remote Antenna Unit. At the same time, the transmission of the feedback signal to the CO/BTS to realize the Digital Pre-Distortion can be very demanding. Indeed, in both cases reported in [24], [25], the information is digital, and at the same time it needs to arrive in real time to the $\mathrm{CO} / \mathrm{BTS}$. It is then required to feedback this signal through internet connection between RAU and BTS. These methodologies anyway further increase cost and complexity of the whole solution.

In the following, we introduce a DPD technique which is put into practice to Multi-Mode (MM)-VCSELMulti-Mode fiber (MMF)-based RoF links where a simplifying approximation on the generation of the mentioned feedback signal is proposed. Indeed, this solution trains the pre-distorter taking a length of a few meters the output of a RoF link which shares the same VCSEL source of the system to be compensated. The feedback signal is in this way generated directly at the $\mathrm{CO}$ and is immediately available to the pre-distorter training block. This approach comprises of the fact that the nonlinearity of the RoF link is mainly induced by the directly modulated VCSEL that utilizes Generalized Memory Polynomial (GMP) model using ILA.

Its effectiveness will be evidenced in the remainder with LTE standard signals, evaluating the transmission performance in terms of reduction of Normalized Mean Square Error (NMSE), Adjacent Channel Power Ratio (ACPR) and Error Vector Magnitude (EVM).

\section{Modeling Approach}

The indirect learning method utilized in Fig. 2 estimates the DPD coefficients in a preliminary training phase. The baseband output of the RoF system converted into digital form $y(n)$ is fed as an input sequence to the Pre-

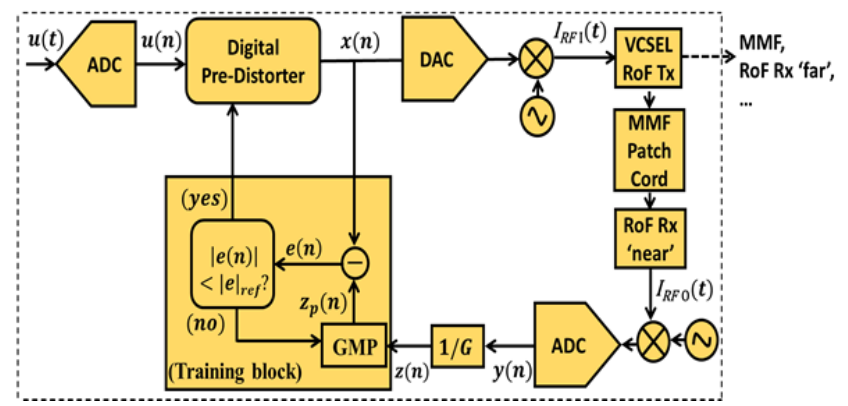

Fig. 2. Block diagram of the training phase of the proposed DPD. 
Distorter Training block via the quantity $z(n)$, defined as $z(n)=y(n) / G$. Here $G$ represents the gain of the RoF link. The coefficients can be estimated with least-squares-algorithm [28]. Once the error function converges, the coefficients are applied to the Digital Pre-Distorter block.

The DPD architecture employed in this work is the Generalized Memory Polynomial (GMP) which was recently applied to RoF based VCSELs [21, 27, 29], is based on the expression:

$$
\begin{aligned}
z_{p}(n) & =\sum_{k=0}^{K_{a}-1} \sum_{q=0}^{Q_{a}-1} a_{k q} z(n-q)|z(n-q)|^{k} \\
& +\sum_{k=1}^{K_{b}} \sum_{q=0}^{Q_{b}-1} \sum_{r=1}^{R_{b}} b_{k q r} z(n-q)|z(n-q-r)|^{k} \\
& +\sum_{k=1}^{K_{c}} \sum_{q=0}^{Q_{c}-1} \sum_{r=1}^{R_{c}} c_{k q r} z(n-q)|z(n-q+r)|^{k} .
\end{aligned}
$$

$z_{p}(n)$ and $z(n)$ represent DPD output and input, respectively. Likewise, the complex coefficients $a_{k q}$ are represented for the signal and envelope while $b_{k q r}$ are the complex coefficients for the signal and lagging envelope while $c_{k q r}$ represents leading signal and envelope. $K_{\mathrm{a}}, K_{\mathrm{b}}, K_{\mathrm{c}}$ are the orders of nonlinearity, $Q_{\mathrm{a}}, Q_{\mathrm{b}}, Q_{\mathrm{c}}$ are the memory depths. $R_{\mathrm{b}}$ shows the lagging delay tap lengths and $R_{\mathrm{c}}$ denotes leading delay tap lengths respectively. GMP was applied choosing optimal values of the coefficients. For simplicity, $K_{\mathrm{a}}=$ $K_{\mathrm{b}}=K_{\mathrm{c}}=K_{\mathrm{GMP}}, \quad Q_{\mathrm{a}}=Q_{\mathrm{b}}=Q_{\mathrm{c}}=Q_{\mathrm{GMP}} \quad$ and $\quad R_{\mathrm{b}}=R_{\mathrm{c}}=R_{\mathrm{GMP}}$ have been chosen.

\section{Experimental Setup}

The experimental setup utilized is given in Fig. 3. The experiments are executed by generating LTE signal of $10 \mathrm{MHz}$ bandwidth with 256 Quadrature Amplitude Modulation (QAM) format. Vector Signal Generator (VSG) Agilent model N5182B MXG X-Series applies the LTE signal to the RoF link. The signal is emulated through a domestic MATLAB code that complies with LTE standard (release 15.2 ETSI TS 136.211).

Initially, the generated LTE frame is modulated onto a RF carrier $f_{\mathrm{c}}=800 \mathrm{MHz}$. The RoF link is comprised of a MM-VCSELs with a patch cord and a link length of MMF with $75 \mathrm{~m}$ and photodiode (PD), having responsivity of $0.22 \mathrm{~A} / \mathrm{W}$.

The Relative Intensity Noise (RIN) of the MM VCSEL is $-125 \mathrm{~dB} / \mathrm{Hz}$ for $f_{\mathrm{c}}=800 \mathrm{MHz}$. The VCSEL biasing current is $I_{\text {bias }}=4 \mathrm{~mA}$, its threshold current is $I_{\text {th }}=0.8 \mathrm{~mA}$ and its maximum current is kept as $I_{\mathrm{s}}=8 \mathrm{~mA}$. Oversampling is carried out at $46.08 \mathrm{MHz}$.

In the training phase of DPD, which corresponds to the positions of the symbolic switches represented in Fig.3, a link consisting of the same VCSEL of the RoF link to be linearized, a MMF patch cord and a photodiode of the same kind of the one utilized in the "far" receiver is utilized for giving the feedback signal to the predistorter training block. This configuration will be called as back-to-back (B2B) case. LTE Reference ( $\mathrm{LTE}_{\mathrm{REF}}$ ) frames are employed in this case where the input/output sequences have to be primarily synchronized in the time domain. This is attained by domestically developed algorithm that calculates the cross-correlation for estimation of time delay. This is done by availing the Primary \& Secondary Synchronization Signals that are already part of the LTE frame. The DPD coefficients are then presented through an in-house developed MATLAB program.

During the testing state, which is also represented by Fig. 3, provided that all the symbolic switches are considered as set in the other position with respect to the depicted one, many LTE frames are sampled, predistorted, sent to the VSG and conveyed through the link utilizing the zerolength case predistorter coefficients found in the training phase. ACPR, NMSE and EVM are then assessed and compared to the case with the output which has not been treated with DPD.

The DPD is tested for general LTE frames. It is worth mentioning the fact that the same training coefficients found during the $\mathrm{B} 2 \mathrm{~B}$ case are utilized, makes this solution straightforwardly feasible, as mentioned in Sec. 1.

Indeed, going back to Fig. 2, the system enclosed by the dashed lines which performs both training and predistortion can be placed at the Central Office, allowing to reduce complexity and cost of the whole system.

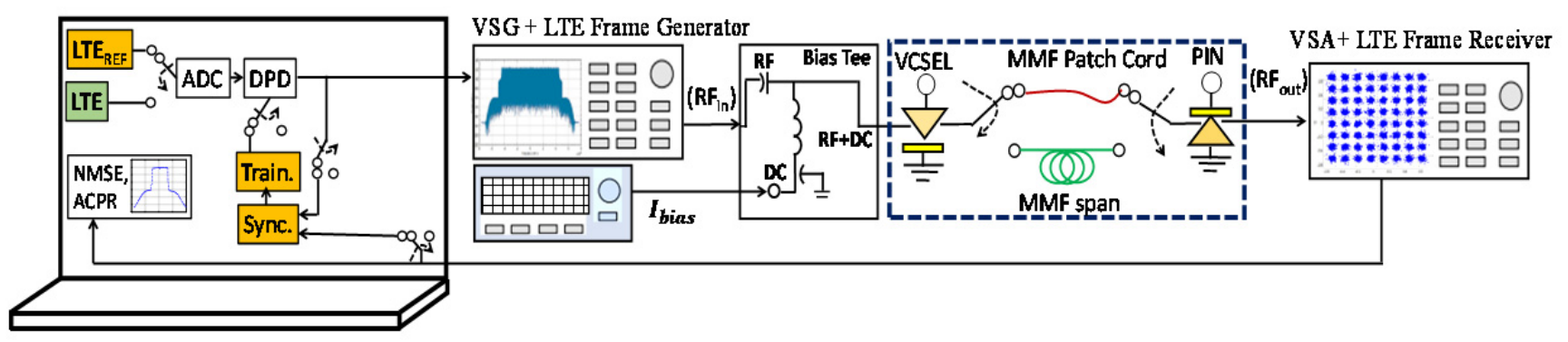

Fig. 3. Experimental bench utilized for the proposed RoF system predistorter. VSA: Vector Signal Analyzer. VSG: Vector Signal Generator. The symbolic switches are represented in the positions corresponding to the training phase. The normal operation of the link is represented by the same figure where all the symbolic switches are set in the other position with respect to the represented one. VSG contains DAC and VSA contains ADC. MMF span represents the fiber length considered. 


\section{Experimental Results and Discussion}

In order to check the efficacy of methodology proposed, the laser is pushed to work near the threshold and compression points so that it can have high Peak to Average Power Ratio generally referred as PAPR and distortions. In order to verify the proposed DPD potency in high distortion critical regions, the biasing current $\left(I_{\text {bias }}\right)$ is set at $2 \mathrm{~mA}$. In this section, ACPR, EVM and NMSE are evaluated as a figure of merit.

Figure 4 presents the results of ACPR improvement in effective form with varying orders of $K_{\mathrm{GMP}}$ and $Q_{\mathrm{GMP}}$ keeping $R_{\mathrm{GMP}}=2$. It can be seen that after $K_{\mathrm{GMP}}=5$ and $Q_{\mathrm{GMP}}=3$, the increasing values of $K_{G M P}$ and $Q_{\mathrm{GMP}}$ do not result in a very vast improvement. Hence, for the evaluations performed, the coefficients $K_{\mathrm{GMP}}=5$ and $Q_{\mathrm{GMP}}=3$ and $R_{\mathrm{GMP}}=2$ are fixed.

It is very important for the proposed method to perform well with increasing RF input powers as change in powers leads to higher PAPR and DPD in such scenarios becomes more critical. Therefore, in Fig. 5, the spectral regrowth in terms of ACPR is measured for different input signal powers $\left(P_{\mathrm{IN}}\right)$. Here, the orders of $K_{\mathrm{GMP}}=5$ and $Q_{\mathrm{GMP}}=3$ are used keeping $R_{\mathrm{GMP}}=2$ as fixed quantity. The trend additionally designates that DPD improvement is in appreciable amount even for the pivotal cases as well. It is evident that with the proposed approximation, the linearization for length cases is same as compared to back to back case. This is obvious that the RoF link nonlinearity is mainly induced by the laser as assumed in our proposed methodology. Indeed, the approximation makes the linearization straightforward without the additional complexity of feedback mechanism.

In Fig. 6, the power spectral density (PSD) also known as spectral regrowth for received signal is demonstrated for the proposed method with and without DPD for $P_{\mathrm{IN}}=0 \mathrm{dBm}$. It can be seen that even with a signal having very high PAPR, working at a region close to threshold, high RF input power, the proposed method works well. The suppression of spectral growth due to linearization performed is in very good proportions.

Figure 7 shows the EVM with and without DPD for varying $P_{\mathrm{IN}}$. The EVM is reported again for two scenarios that comprise of $\mathrm{B} 2 \mathrm{~B}$ and $75 \mathrm{~m}$ length case. The proposed DPD method results in similar EVM curves for B2B and $75 \mathrm{~m}$ length case. Indeed, with the presented DPD method, the $3.5 \%$ EVM limit set by 3 GPP is met. This further substantiates the advantages of the DPD as it results in the suppression of nonlinearities and brings EVM correction within the limits. For instance, at a very high RF input power of $0 \mathrm{dBm}$, EVM for $75 \mathrm{~m}$ without DPD is 7\%. However, with the proposed technique, DPD results in EVM for $\mathrm{B} 2 \mathrm{~B}$ and $75 \mathrm{~m}$ length results in EVM of $3.4 \%$. This means that the proposed method increases the admissible "Dynamic range" of input power by $5 \mathrm{dBs}$.

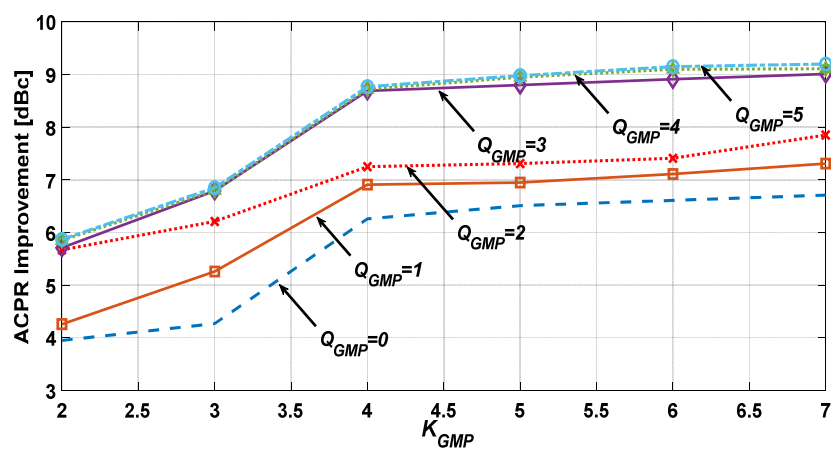

Fig. 4. ACPR improvement with proposed DPD technique for different orders of nonlinearity $K_{\mathrm{GMP}}$ and memory length $Q_{\mathrm{GMP}}$ at $0 \mathrm{dBm}$ of input power.

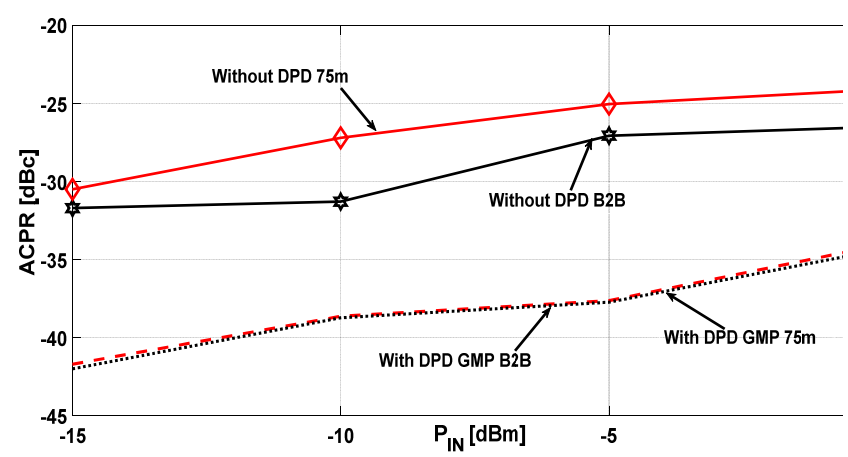

Fig. 5. Output signal without DPD and with DPD for back to back ( $0 \mathrm{~m}$ length) and $75 \mathrm{~m} \mathrm{MMF}$ at $0 \mathrm{dBm}$ of input signal power.

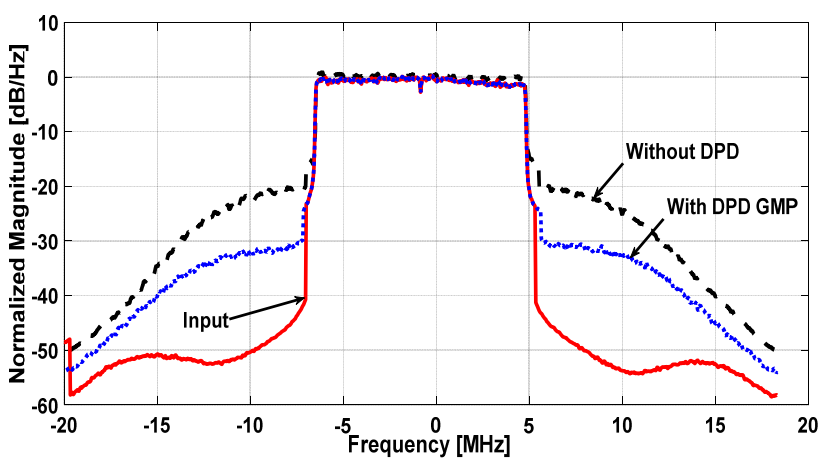

Fig. 6. Comparison of output signal without and with DPD for back to back ( $0 \mathrm{~m}$ length) and $75 \mathrm{~m}$ length at $0 \mathrm{dBm}$ input signal power.

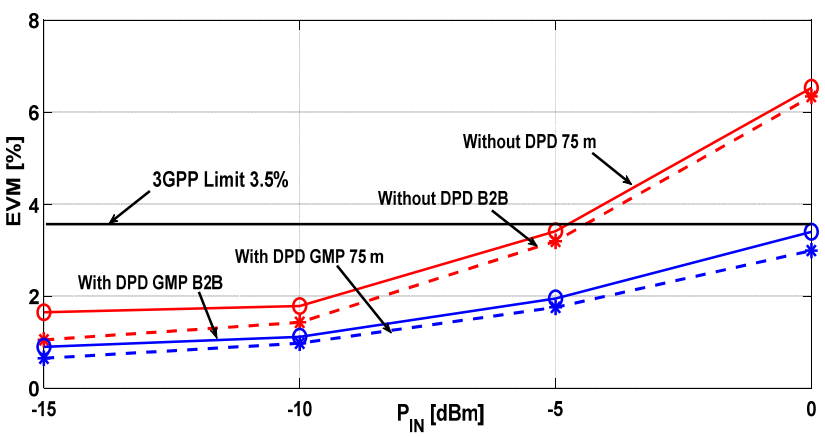

Fig. 7. EVM comparison for DPD and without DPD for varying $P_{\mathrm{IN}}$. 


\begin{tabular}{|c|c|c|c|}
\hline Model & NMSE (dB) & ACPR (dBc) & EVM (\%) \\
\hline$N o D P D$ & -24.10 & -24.13 & 6.4 \\
\hline$G M P-D P D$ & -36.14 & -33.81 & 3.3 \\
\hline
\end{tabular}

Tab. 1. Linearization performance with input power of $0 \mathrm{dBm}$.

It must be noted that in real time scenarios, this methodology is applicable for higher lengths cases as well. The $75 \mathrm{~m}$ length is just considered for the demonstration purposes. This means, that laser has been linearized with proposed feedback locally at the base station and the computed coefficients through DPD can be applied for the length cases which will enhance the linearization as compared to non-compensated cases.

There is another important consideration that must be addressed. In the discussed scenario, we have shown MMVCSEL with MMF. Since DPD without the feedback approximation shown in this work has been validated in [29] both for Single Mode VCSEL-Single Mode Fiber and Multi-Mode VCSEL-Multi Mode Fiber. In this work, the intention for choosing this scenario is the realistic validation of practical scenarios as discussed in [14-16] where MM-VCSEL with MMF have been utilized.

Note that the proposed DPD is functional for longer link distances and higher bandwidth if model is extracted with right $Q$ and/or $K$. Indeed, with the higher modulation format and higher bandwidth like multiple LTE carriers or $5 \mathrm{G}$ new radio waveforms, they would lead to higher complexity of DPD operation due to stronger PAPR. Concomitantly, the elevation in bandwidth will lead to overall increase in the baseband memory of the system model. Nevertheless, the evaluated models are still valid. However, higher values of $Q$ and $K$ will be indispensable as compared to the considered case.

Table 1 summarizes the results for with and without DPD. It can be seen that the proposed method linearizes the link in good proportions.

\section{Conclusions}

This paper presents the experimental evaluation of DPD for RoF mobile fronthaul with feedback approximation for MM-VCSEL based RoF links. These experiments were accomplished with MM-VCSEL based RoF link with $10 \mathrm{MHz}$ LTE signal having 256 QAM modulation. The proposed feedback approximation does not only reduce the overall cost, but also removes the complexities required to carefully handle the own nonlinearities of feedback loop. Appreciable performance improvements were obtained in terms of ACPR, NMSE and EVM. It was shown that linearization with the proposed feedback approximation is obtained in good proportions. The detailed evaluation with higher link lengths is envisaged for future work.

\section{References}

[1] GUPTA, A., JHA, R. K. A survey of 5G network: Architecture and emerging technologies. IEEE Access, 2015, vol. 3, p. 1206-1232. DOI: 10.1109/ACCESS.2015.2461602

[2] SHI, Y., VISANI, D., OKONKWO, C. M., et al. First demonstration of HD video distribution over large-core POF employing UWB for in-home networks. In Optical Fiber Communication Conference (OFC). Los Angeles (CA, USA), 2011, p. 1-3. DOI: 10.1364/ofc.2011.owb5

[3] HADI, M. U., JUNG, H., GHAFFAR, S., et al. Optimized digital radio over fiber system for medium range communication. Optics Communications, 2019, vol. 443, p. 177-185. DOI: 10.1016/j.optcom.2019.03.037

[4] LAU, K. Y. RF transport over optical fiber in urban wireless infrastructures. IEEE/OSA Journal of Optical Communications and Networking, 2012, vol. 4, no. 4, p. 326-335. DOI: 10.1364/JOCN.4.000326

[5] HADI, M. U., HADI, M. U., ASLAM, N., et al. Experimental demonstration of MASH based sigma delta radio over fiber system for 5G C-RAN downlink. Journal of Optical Communication, 2019. DOI: 10.1515/joc-2019-0011

[6] SHI, Y., OKONKWO, C. M., VISANI, D., et al. Ultrawideband signal distribution over large-core POF for in-home networks. Journal of Lightwave Technology, 2012, vol. 30, no. 18, p. 2995 to 3002. DOI: 10.1109/JLT.2012.2210538

[7] KHURSHID, K., KHAN, K. K., SIDDIQUI, H., et al. Big data assisted CRAN enabled 5G SON architecture. Journal of ICT Research and Applications, 2019, vol. 13, no. 2, p. 93-106. DOI: 10.5614/itbj.ict.res.appl.2019.13.2.1

[8] CHINA MOBILE RESEARCH INSTITUTE. C-RAN: the Road towards Green RAN. White Paper, Beijing (China), 2013, p. 1-48.

[9] LI, Y., SATYANARAYANA, K., EL-HAJJAR, M., et al. Analogue radio over fiber aided MIMO design for the learning assisted adaptive C-RAN downlink. IEEE Access, 2019, vol. 7, p. 21359-21371. DOI: 10.1109/ACCESS.2019.2897922

[10] RANAWEERA, C., LIM, C., WONG, E., et al. Planning and dimensioning of optical transport networks for $5 \mathrm{G}$ and beyond. In IEEE Photonics Society Summer Topical Meeting Series (SUM). Ft. Lauderdale (FL, USA), 2019, p. 1-2. DOI: 10.1109/PHOSST.2019.8795061

[11] LI, Y., GHAFOOR, S., SATYANARAYANA, K., et al. Analogue wireless beamforming exploiting the fiber-nonlinearity of radio over fiber-based C-RANs. IEEE Transactions on Vehicular Technology, 2019, vol. 68, no. 3, p. 2802-2813. DOI: 10.1109/TVT.2019.2893589

[12] PESSOA, L. M., TAVARES, J. S., COELHO, D., et al. Experimental evaluation of a digitized fiber-wireless system employing sigma delta modulation. Optics Express, 2014, vol. 22, no. 14 , p. $17508-17523$. DOI: $10.1364 /$ OE.22.017508

[13] AlCARO, G., VISANI, D., TARLAZZI, L., et al. Distortion mechanisms originating from modal noise in radio over multimode fiber links. IEEE Transactions on Microwave Theory and Techniques, 2012, vol. 60, no. 1, p. 185-194. DOI: 10.1109/TMTT.2011.2171982

[14] VISANI, D., TARTARINI, G., PETERSEN, M. N., et al. Link design rules for cost-effective short-range radio over multimode fiber systems. IEEE Transactions on Microwave Theory and 
Techniques, 2010, vol. 58, no. 11, p. 3144-3153. DOI: 10.1109/TMTT.2010.2074552

[15] VISANI, D., OKONKWO, C. M., LOQUAI, S., et al. Record 5.3 $\mathrm{Gbit} / \mathrm{s}$ transmission over $50 \mathrm{~m} 1 \mathrm{~mm}$ core diameter graded-index plastic optical fiber. In Optical Fiber Communication Conference, (OFC 2010). San Diego (CA, USA), 2010, p. 1-3. DOI: 10.1364/NFOEC.2010.PDPA3

[16] SAUER, M., KOBYAKOV, A., BOH RUFFIN, A. Radio-overfiber transmission with mitigated stimulated brillouin scattering. IEEE Photonics Technology Letters, 2007, vol. 19, no. 19, p. 1487-1489. DOI: 10.1109/LPT.2007.903765

[17] MEDINA SEVILA, P., ALMENAR, V., CORRAL, J. L. Transmission over SSMF at $850 \mathrm{~nm}$ : Bimodal propagation and equalization. Journal of Lightwave Technology, 2017, vol. 35, no. 19 , p. 4125-4136. DOI: $10.1109 / J L T .2017 .2726585$

[18] VISANI, D., SHI, Y., OKONKWO, C. M., et al. Wired and wireless multi-service transmission over $1 \mathrm{~mm}$-core GI-POF for inhome networks. Electronics Letters, 2011, vol. 47, no. 3, p. 203 to 205. DOI: $10.1049 / \mathrm{el} .2010 .7273$

[19] AMARI, A., LIN, X., DOBRE, O. A., et al. A machine learning based detection technique for optical fiber nonlinearity mitigation. IEEE Photonics Technology Letters, 2019, vol. 31, no. 8, p. 627 to 630. DOI: 10.1109/LPT.2019.2902973

[20] WEISS, J. Analog optical RF-links for large radio telescopes. In IEEE BiCMOS and Compound Semiconductor Integrated Circuits and Technology Symposium (BCICTS). San Diego (CA, USA), 2018, p. 24-27. DOI: 10.1109/BCICTS.2018.8551058

[21] HADI, M. U., TRAVERSO, P. A., TARTARINI, G., et al. Digital predistortion for linearity improvement of VCSEL-SSMF-based radio-over-fiber links. IEEE Microwave and Wirless Components Letters, 2019, vol. 29, no. 2, p. 155-157. DOI: 10.1109/LMWC.2018.2889004

[22] VIEIRA, L. C., GOMES, N. J., NKANSAH, A., et al. Behavioral modeling of radio-over-fiber links using memory polynomials. In 2010 IEEE International Topical Meeting on Microwave Photonics. Montreal (QC, Canada), 2010, p. 85-88. DOI: 10.1109/MWP.2010.5664204

[23] FUOCHI, F., HADI, M. U., NANNI, J., et al. Digital predistortion technique for the compensation of nonlinear effects in radio over fiber links. In 2016 IEEE 2nd International Forum on Research and Technologies for Society and Industry Leveraging a Better Tomorrow (RTSI). Bologna (Italy), 2016, p. 1-6. DOI: 10.1109/RTSI.2016.7740562

[24] MATeO, C., Clemente, J., GARCIA-DUCAR, P., et al. Linearization of a radio-over-fiber mobile fronthaul with feedback loop. In 2017 26th Wireless and Optical Communication Conference (WOCC). Newark (NJ, USA), 2017, p. 1-6. DOI: 10.1109/WOCC.2017.7928986

[25] HeKKala, A., HiIVAla, M., LASANEN, M., et al. Predistortion of radio over fiber links: Algorithms, implementation, and measurements. IEEE Transactions on Circuits and Systems I: Regular Papers, 2012, vol. 59, no. 3, p. 664-672. DOI: 10.1109/TCSI.2011.2167267

[26] MATEO, C., CARRO, P. L., GARCIA-DUCAR, P., et al. Digital predistortion based on B-spline CPWL models in a RoF LTE mobile fronthaul. In 2017 12th European Microwave Integrated Circuits Conference (EuMIC). Nuremberg (Germany), 2017, p. 396-399. DOI: 10.23919/EuMIC.2017.8230742

[27] HADI, M. U., KANTANA, C., TRAVERSO, P. A., et al. Assessment of digital predistortion methods for DFB-SSMF radioover-fiber links linearization. Microwave and Optical Technology Letters, 2020, vol. 62, no. 2, p. 540-546. DOI: 10.1002/mop.32073

[28] MORGAN, D. R., MA, Z., KIM, J., et al. A generalized memory polynomial model for digital predistortion of RF power amplifiers.
IEEE Transactions on Signal Processing, 2006, vol. 54, no. 10, p. 3852-3860. DOI: 10.1109/TSP.2006.879264

[29] HADI, M. U., NANNI, J., VENARD, O., et al. Linearity improvement of VCSELs based radio over fiber systems utilizing digital predistortion. Advances in Science, Technology and Engineering Systems Journal, 2019, vol. 4, no. 3, p. 156-163. DOI: $10.25046 /$ aj040321

\section{About the Authors ...}

Muhammad Usman HADI received the B.S. degree in Electrical Engineering from PIEAS, Islamabad, Pakistan, in 2014, and the M.Sc. degree in Electronic Engineering from the University of Bologna, Italy, in 2016. Since November 2016, he is pursuing the Ph.D. degree in Microwave Photonics with the Optics Lab, University of Bologna. He was a Visiting Researcher (2018-2019) at Université Paris-Est, ESYCOM, ESIEE Paris, Noisy-le-Grand, France. In 2018, he was a Visiting Researcher at Nokia Bell Labs. His research interests are in the area of linearization and signal processing for microwave photonics, including RoF systems and devices for telecommunications and wireless sensor networks. He serves as a Reviewer for the IEEE Communications Letters, IEEE Access, SPIE, ASTSEJ, and IET-OptoElectronics.

Jacopo NANNI received the B.Sc. and M.Sc. degrees in Telecommunications Engineering from the University of Bologna in 2012 and 2015, respectively, and the double $\mathrm{Ph} . \mathrm{D}$. degrees from the University of Bologna, Italy, and from Université Paris-Est, ESYCOM, ESIEE Paris, Noisyle-Grand, France, in 2018. Since 2015, he has been with the Department of Electrical, Electronic and Information Engineering (DEI) "Guglielmo Marconi”, Università di Bologna, as a Research Fellow, working on low cost and low consumption VCSEL-based radio-over-fiber systems for indoor and radio-astronomy applications. He is currently working on RoF systems for low cost cellular network infrastructures and in the field of radio-astronomy within the square kilometer array (SKA) project. Moreover, part of his work is dedicated to the study of optical wireless networks on-chip and the optimization of low cost optical coupling structures.

Olivier VENARD received the M.Sc. in Electronics, Sensors and Signal Processing from Université Paris-Sud Orsay in 1996. After being involved on network technologies and embedded electronics at Centre National d'Etude des Telecommunication (Paris), He is now an Associate Professor at ESIEE and a member of ESYCOM laboratory, Université Paris-Est. His research and teaching interests cover the following topics: signal processing algorithms for sensors and digital communications, non-linear signal processing for linearisation, adaptive signal processing, wireless communications, networks protocols, embedded electronics and IoT.

Geneviève BAUDOIN received the bachelor's degree from the Ecole Nationale Supérieure des Télécommunica- 
tions, Paris, France, in 1977, and the Ph.D. degree from the University of Marne La Vallée, Marne La Vallée, France, in 2000. She was a Lecturer with the University of ParisOuest, Nanterre, France. She joined the Philips Research Laboratory, as a Research Engineer, where she was involved in ultrasound signal processing for medical applications. She is currently a Professor with ESIEE Paris, Noisyle-Grand, France, where she is the Chair of the System Engineering Department. She is a member of the ESYCOM Research Laboratory, Université Paris-Est Marne-la-Vallée, Champs-sur-Marne, France. Her current research and teaching interests include digital signal processing, wireless communications, wireless transmitter linearization, transceiver architectures and algorithms for wireless communications and localization systems.

Jean-Luc POLLEUX received the master's degree and Diplôme d'ingénieur in Microelectronic from ENSEIRB, Bordeaux, France, the D.E.A. degree in Electronic and Telecommunications from the University of Bordeaux 1, France, in 1997, and the Ph.D. degree in the Opto-microwave Field from CNAM, Paris, in 2001. He then joined ESIEE-Paris at Université Paris-Est (UPE), France, and the joint laboratory ESYCOM. He has been animating the Institute DIAMON, a Paris Region French Cluster of Research, since 2015. He is currently an Associate Professor. $\mathrm{He}$ is also an administrator of Optics Valley, Ile-de-France region, and the Head of the International Master of Electronics, ESIEE Paris, Université Paris-Est. He published more than 90 scientific publications and two patents. His current research involves microwave-photonics devices and systems for radio-over-fibre applications with special emphasis on microwave phototransistors ( $\mathrm{SiGe} / \mathrm{Si}$ and InGaAs/InP), silicon-based integration and packaging, analogue VCSELs and opto-microwave devices modeling. He co-organized three international workshops, co-chaired the French National Microwave Conference, JNM, in 2013, and chaired and co-chaired the Career Platform of EuMW in 2015 and 2016. He was a Guest Editor of the International Journal of Microwave and Wireless Technologies (IJMWT) in 2014, and is an Associate Editor for the Silicon-Based Optoelectronics Special Issue of the SPIE Journal of Nanophotonics.

Giovanni TARTARINI was responsible for the University of Bologna of the integrated project Architectures for Flexible Photonic Home and Access Networks (ALPHA), from 2008 to 2011, sponsored by the European Community in the VII Research Framework Program. Since 2013, he has been responsible of a collaboration with the Italian Institute of Astrophysics for the development and characterization of Radio over Fiber links within the International Radio-Astronomy Project named Square Kilometer Array (SKA). He is currently an Associate Professor of electromagnetic fields with the Department of Electrical, Electronic and Information Engineering (DEI), Università di Bologna. He collaborates on these topics with private companies and research institutions. His research interests are in the area of microwave photonics, including radio over fiber systems and devices for telecommunications (outdoor and in-building wireless signal distribution) and sensing (radio-astronomic and UWB signal transmission). 